\title{
Research on the development of membrane bioreactor technology
}

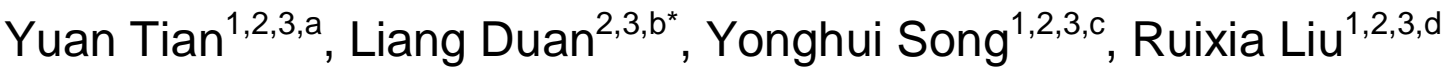 \\ ${ }^{1}$ College of Water Science, Beijing Normal University, Beijing, 100018, China \\ ${ }^{2}$ State Key Laboratory of Environmental Criteria and Risk Assessment, Chinese Research \\ Academy of Environmental Sciences, Beijing, 100012, China \\ ${ }^{3}$ Department of Urban Water Environmental Research, Chinese Research Academy of \\ Environmental Sciences, Beijing, 100012, China \\ "Corresponding author \\ aemail: 1002106371@qq.com, bemail: duanliang@craes.org.cn, cemail: songyh@craes.org.cn, \\ demail: liurx@craes.org.cn
}

Keywords: membrane bioreactor, wastewater treatment, development

Abstract: Membrane bioreactor (MBR) technology is composed of membrane separation and biological disposal processes, which is a new wastewater treatment technique with high efficiency. It has been widely applied in municipal and industrial wastewater treatment due to the unique advantages of high-quality effluent, small footprint and stable operation. This paper discussed the major types and characteristics of MBR and then the development and application of MBR were also elaborated; furthermore, the foreseeable challenges on the promotion of MBR were analyzed.

\section{Introduction}

Rapid development of industry and acceleration of urbanization have brought severe environmental problems. The large number of wastewater discharge particularly has caused a serious shortage of water resources. Water shortage and pollution had increasingly restricted the society progress in both developing and developed countries. Therefore, wastewater reclamation and reuse was considered as an effective method for sustainable development [1]. In view of this, compared with traditional activated sludge process, membrane bioreactor (MBR) emerged with distinct advantages of high-quality effluent, low footprint, less sludge production and longer solid retention times (SRT) [2].

MBR technology is a combination of a membrane separate unit and a biological process unit. The membrane unit can separate the treated water from mixed liquor and retain small molecular micropollutants [3]. The biological unit is responsible for degradation of organic contaminants. MBR was firstly applied in the field of animalcule fermentation, and then began to resolve the domestic sewage pollution in the 1960s [4]. More attention had been gradually paid to the application and research of MBR for industrial wastewater treatment. Nowadays, MBR technology has been widely used for the treatment and reclamation of municipal wastewater, industrial wastewater and drinking water [5].

\section{The main types of MBR}

The original MBR consist of two parts, membrane module and aerated sludge reactor. As shown in Fig. 1, according to the placement of membrane module, MBR are divided into two major categories: split MBR and submerged MBR [6]. 
Split MBR was the earlier type of MBR. Membrane module unit and bioreactor are kept apart in split MBR, which are connected through the peristaltic pump and pump pipe. Due to the independent system, split MBR has the advantages of convenient operation and management, easily washed and replaced to the membrane module. However, compared with the submerged MBR, it has the drawbacks of large area occupied, serious membrane fouling and great energy consumption.

In order to solve the energy-intensive problem of split MBR, Yamamoto et al. developed the submerged MBR in 1989 [7]. It has the advantages of compact construction, less occupied area and low energy cost. However, the submerged MBR is not as convenient as spilt type in the washing and replacing of the membrane module.

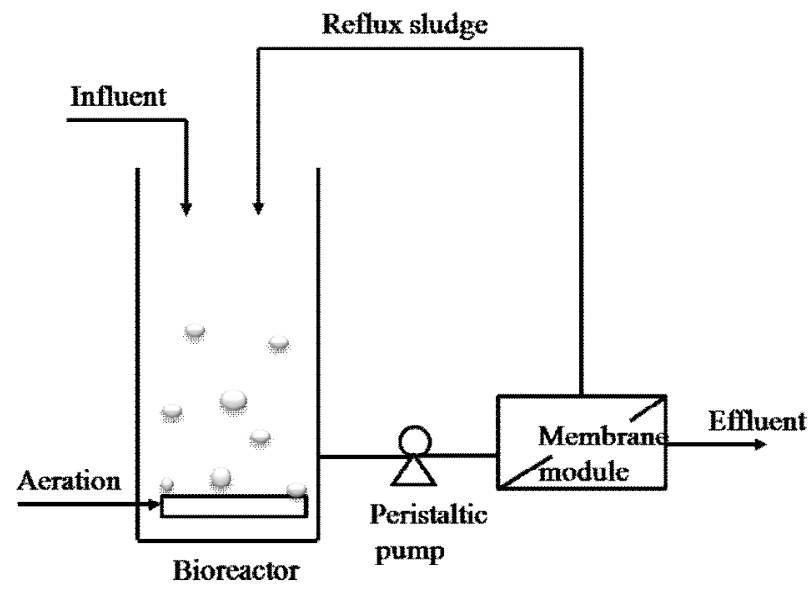

(a) Split membrane bioreactor

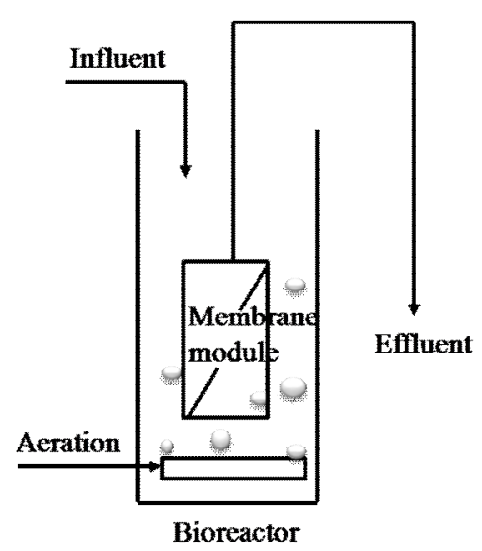

(b) Submerged membrane bioreactor

Fig. 1 Two types of MBR

\section{The characteristics of MBR}

MBR technology makes full use of the space and the ability of microorganism degradation. As a new sewage treatment technology, MBR is a significant combination of bioreactor and membrane separation technology. It shows unique advantages in wastewater treatment and also has some shortcomings at the same time. The main process characteristics of MBR are as follow: (1) It overcomes the problem of sludge bulking compared with traditional activated sludge process; (2) It has stable water quality, high removal efficiency of pollutants and the effluent can be directly reused; (3) MBR carries out the separation of sludge retention time (SRT) and hydraulic retention time (HRT) thoroughly, making the MBR simple to design and easy to operate [8]; (4) The SRT is extended by membrane interceptive role. Therefore, lower excess sludge production brings a decreasing costs in processing; (5) MBR has a better removal ability of nitrogen and phosphorus compared with conventional activated sludge method [9]; (6) The accumulation of hard-degraded substances induce membrane fouling. The cleaning and replacement of membrane module cause a lot of inconvenience for management and increase operation costs.

\section{The development and application of MBR}

As one of the most new promising technologies in the $21^{\text {st }}$ century, the research and application of MBR in wastewater treatment have attracted more attention worldwide. The research of MBR in wastewater treatment started in the 1960s. Dorr-Oliver Company reported the research results of MBR technology at the meeting of the American Chemical Society in 1966. Then Smith combined the ultrafiltration with activated sludge process to treat municipal wastewater for the first time in 
1969, which was a prototype of MBR [10]. However, the stable operation and practical usage of MBR were impeded, since the limitation of membrane production technique, few species and short lifespan of membrane module. Even so, MBR technology still attracted the attentions of many researchers all over the world.

Considering the narrow territory area, the short distance of surface run-off, the weak ability of self-purification and the vulnerable water system, specialists and scholars of Japan began to focus on the research and application of membrane separation technology in sewage treatment and reuse after 1970s [11]. The development and popularization of MBR were energetically encouraged. Since 1980s, with the development of membrane production technology, the improvement of membrane separation technique and washing method, MBR wastewater treatment technology became more and more popular in sewage treatment industry.

Since 1990s, the processing objects of MBR were extended from municipal sewage to high concentration and hard-degraded petrochemical wastewater, pharmacy wastewater, landfill leachate and papermaking wastewater. The commercialization of MBR was developed gradually. The Zenon Corporation of Canada and the Kubota Corporation of Japan were the earliest company to apply MBR to commercial development [12]. Although MBR technology had been used widely in the world, high energy consumption and membrane fouling were the major factors for limiting the promotion of this technology $[13,14]$.

In the middle of 1990s, more Chinese researchers had focused on using the MBR to treat various wastewaters, but the MBR research was developed rapidly in recent years. Many colleges and research institutes joined in the exploitation and research of MBR in 1993. Xing from Tsinghua University used inorganic MBR to treat sewage in his research at 1998. Recently, most studies of MBR mainly concentrate on operation mode, optimized parameters, membrane fouling and its prevention, new membrane materials and membrane module [15]. There have been substantial improvement and technological advancement in the development of MBR. Although the problems of membrane fouling and high energy consumption are not thoroughly resolved, MBR has the incomparable advantages compared to traditional water treatment process. In the last few years, the research of organic polymer materials has achieved great development, which is more conductive to the promotion and application of MBR technology.

\section{Conclusions}

With the rapid development of industry, water shortage and pollution are increasing serious. MBR technology has been proved to be an efficient tool for wastewater treatment and reuse due to the advantages of high quality effluent, strong capacity for shock loads, convenient maintenance and stable operation. However, the practical application of MBR still exist many problems to be resolved such as membrane fouling, high energy consumption, expensive membrane module. The challenges on the promotion of MBR can be considered to (1) develop new membrane materials with high performance and cost-effectiveness, (2) strengthen the control of membrane fouling, and (3) optimize technological process of MBR. With the rapid development and maturity of MBR, it will become an efficient, economical and practical technology in the future.

\section{Acknowledgements}

This study was supported by the Major Science and Technology Program for Water Pollution Control and Treatment (2014ZX07216-001-2), the National Natural Science Foundation of China 
(No. 51108437) and Foundation of State Environmental Protection Key Laboratory of Microorganism Application and Risk Control (SMARC. 2013D005)

\section{References}

[1] B. Lesjean and E.H. Huisjeslow: Desalination Vol. 231 (2008), p. 71-81.

[2] J. Hoinkis, S.A. Deowan and V. Panten: Procedia Eng. Vol. 33 (2012), p. 234-241.

[3] L.Y. Huang and D.J. Lee: Bioresour. Technol. Vol. 194 (2015), p. 383-388.

[4] D.L. Van and G. Roncken: Water Sci. Technol. Vol. 35 (1997), p. 35-41.

[5] T. Melin, B. Jefferson and D. Bixio: Desalination Vol. 187 (2006), p. 271-282.

[6] S. Judd: Trends Biotechnol. Vol. 26 (2008), p. 109-116.

[7] Y. Kazuo and M.W. Khin: Water Sci. Technol. Vol. 7-9 (1991), p. 1639-1648.

[8] D.R. Van, B. Van and D. Lawrence: Water Sci. Technol. Vol. 4-5 (2002), p. 273-280.

[9] L. Holakoo, N. George and S.B. Amarjeet: Chemosphere Vol. 66 (2007), p. 849-857.

[10] M. Clara, S. Birgit and G. Oliver: Water Res. Vol. 39 (2005), p. 4797-4807.

[11] C. Chiemchaisri and Y. Kazuo: J. Membr. Sci. Vol. 87 (1994), p. 119-129.

[12] B. Verrecht, M. Thomas and N. Ingmar: Water Res. Vol. 44 (2010), p. 5274-5283.

[13] Y. Miura, N.H. Mirian: Water Res. Vol. 41 (2007), p. 627-637.

[14] F.G. Meng, C. Song and D. Anja: Water Res. Vol. 43 (2009), p. 1489-1512.

[15] C.P. Le: Appl. Microbiol. Biotechnol. Vol. 88 (2010), p. 1253-1260. 